\title{
EFFECTS OF GEOMETRIC PARAMETERS ON ENTROPY GENERATION IN FIRE-TUBE STEAM BOILER'S HEAT EXCHANGER
}

\author{
OLUMUYIWA LASODE ${ }^{1}$, JOSEPH OYEKALE ${ }^{2 *}$, IDEHAI OHIJEAGBON ${ }^{1}$, JOHN \\ OLADEJI ${ }^{3}$ \\ ${ }^{1}$ Department of Mechanical Engineering, University of Ilorin, P.M.B. 1515, Ilorin, Nigeria \\ ${ }^{2}$ Department of Mechanical Engineering, Federal University of Petroleum Resources, Effurun, \\ P.M.B. 1221, EFFURUN, Nigeria \\ ${ }^{3}$ Department of Mechanical Engineering, Ladoke Akintola University of Technology, P.M.B. \\ 4000, Ogbomoso, Nigeria
}

\begin{abstract}
This paper presents a parametric study on fire-tube steam boilers' heat exchanging unit using Entropy Generation Minimization (EGM) technique. Mathematical equation that models entropy generation rate $\left(\dot{\mathrm{S}}_{\mathrm{gen}}\right)$, and entropy generation number $\left(\mathrm{N}_{\mathrm{s}}\right)$, were formulated. The entropy generation number was related to the geometric features of the system. Solving the equations showed the effects of each geometric feature on both pressure drop and $\mathrm{N}_{\mathrm{s}}$. Correlation equation relating dimensionless fire-tube length to dimensionless tube diameter was also obtained. The obtained correlation equation is a tool to be incorporated into fire-tube steam boiler design, so as to account for entropy generation during design.
\end{abstract}

Keyword: entropy generation minimization, heat exchanging unit, geometric features

\section{INTRODUCTION}

Entropy is a measure of the extent of disorderliness/randomness in a thermodynamic system. It can be used to distinguish between reversible and irreversible processes [1]. Its analysis can be used to assess the level of energy quality in a system. Entropy generation rate investigates irreversibility by the second law of thermodynamics $[2,3]$. Determination of entropy generation is also important to enhance system performance because entropy generation measures destruction of available work in the system [4].

Entropy Generation Minimization (EGM) is a method of optimization of the thermodynamic imperfections and fluid flow irreversibility [5]. It involves the use of the deterministic or heuristic approach to investigate the area with the highest rate of entropy generation in a system, as well as the cause(s) of such entropy generation. It also uses either of these approaches to minimize entropy in a system, thereby increasing the useful work or energy of the system [6]. Recent application of EGM includes its use in parametric studies.

Parametric study of entropy minimization on the heat exchanging unit of steam boilers has become very important, in view of high premium placed on the use of steam boilers for various industrial processes. Steam boilers are those closed vessels which are used in the production of steam from water by combustion of fuel [7]. The steam produced finds applications in many other production processes. Thus, it is very important to

\footnotetext{
* Corresponding Author, email: oyekale.oyetola@,fupre.edu.ng

(C) 2015 Alma Mater Publishing House
} 
effectively assess the energy resources utilization and outputs in steam boilers to ensure adequate energy management [8]. Steam boilers have various components, but the component which is responsible for the phase change of water is the heat exchanging unit [9]. It is placed directly after the combustion unit, and it exemplifies a cross flow heat exchanger type. It takes in the hot flue gas coming out of the combustion unit, and the heat carried by this gas is used to transform liquid water to steam in the unit [10]. According to Bejan [11], exergy analysis and the minimization of exergy destruction can be used by themselves especially in areas where the total cost of the installation is dominated by the cost due to thermodynamic irreversibility. Steam boilers heat exchanger can be conceptualized on the basis of entropy generation minimization, considering its objectives and physical constraint.

Although many complex analyses of EGM on heat exchangers have been reported before now, the vast majority of them focused on actual optimization of the studied systems based on thermodynamic properties, while just very few of such analyses studied parametric effects of system geometry on EGM. This work aims to investigate the effects of fire-tube geometric parameters on entropy generation in the fire-tube steam boilers' heat exchanging unit. Investigating the effects of 'size' on the performance of steam boiler's heat exchanger as it is done in this study is theoretically similar to what obtains in constructive designs, where flow configurations are generated in energy conversion systems for optimum performance of such systems [12-15]. Mathematical equation that models entropy generation rate in the steam boiler will be formulated from fundamental entropy equation. This model will be derived from schematic illustration of steam boiler heat exchanging unit. Available thermodynamic properties for a fire-tube steam boiler [16] will be used for the parametric analysis.

\section{MATHEMATICAL REPRESENTATION OF SYSTEM'S ENTROPY GENERATION RATE}

The schematic of the control volume of the system is shown in Figure 1.

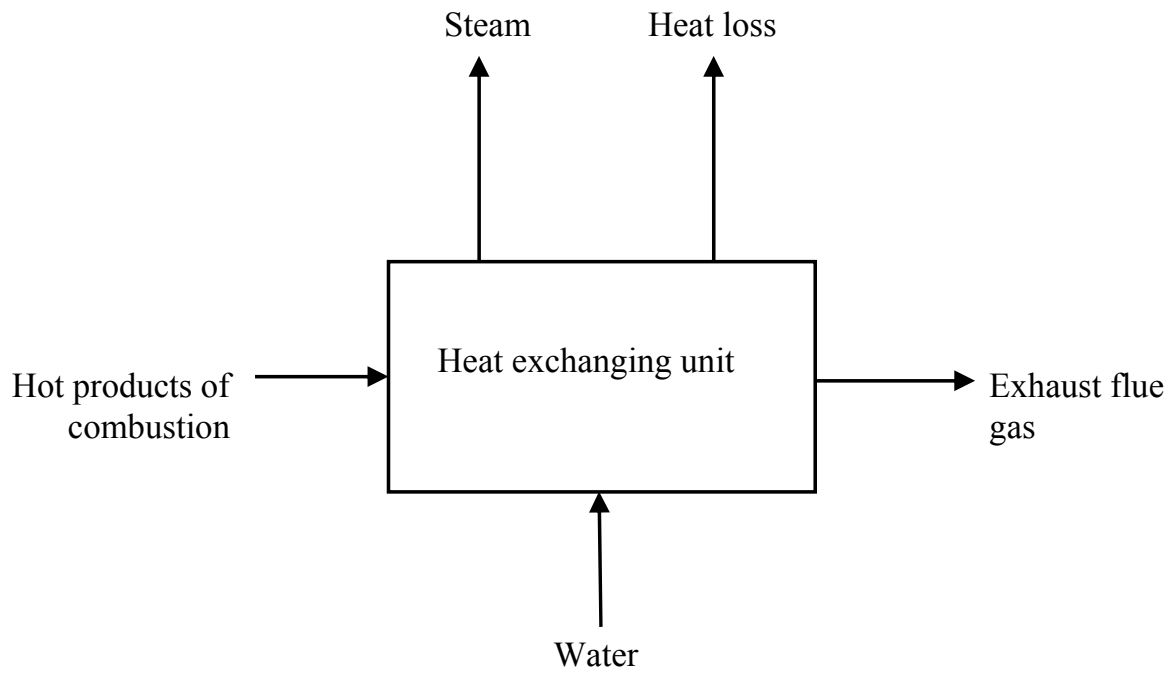

Fig. 1. Schematic diagram of heat exchanging units in steam boilers [7].

Considering Figure 1, there are two streams flowing through the heat exchanging unit, hot products of combustion, and water. Entropy generation rate in the heat exchanging unit is due to the two streams and heat loss, and it is expressed as

$$
\dot{\mathrm{S}}_{\mathrm{gen}}=\dot{\mathrm{m}}_{\mathrm{p}}\left(\mathrm{c}_{\mathrm{pp}} \operatorname{In} \frac{T_{g}}{T_{p}}-\mathrm{R}_{\mathrm{p}} \operatorname{In} \frac{P_{g}}{P_{p}}\right)+\dot{\mathrm{m}}_{\mathrm{w}}\left(\mathrm{c}_{\mathrm{pw}} \operatorname{In} \frac{T_{s}}{T_{w}}-\mathrm{R}_{\mathrm{w}} \operatorname{In} \frac{P_{s}}{P_{w}}\right)+\frac{Q_{l}}{T_{a}}
$$

where:

$$
Q_{l}=\text { heat loss }=\dot{\mathrm{m}}_{\mathrm{p}} \mathrm{c}_{\mathrm{pp}}\left(\mathrm{T}_{\mathrm{g}}-\mathrm{T}_{\mathrm{p}}\right)+\dot{\mathrm{m}}_{\mathrm{w}} \mathrm{c}_{\mathrm{pw}}\left(\mathrm{T}_{\mathrm{s}}-\mathrm{T}_{\mathrm{w}}\right)
$$


The first term on the right hand side of equation (1) is the entropy generation rate due to the hot product stream, while the second term is the entropy generation rate due to the water stream. The third term is the entropy generation rate due to heat loss in the system.

\subsection{Non-dimensionalization of Entropy Generation Rate}

Capacity flow rate on the water side is expressed as:

$$
\mathrm{C}_{\max }=\dot{\mathrm{m}}_{\mathrm{w}} \mathrm{c}_{\mathrm{pw}}
$$

and that on the hot product side is:

$$
\mathrm{C}_{\min }=\dot{\mathrm{m}}_{\mathrm{p}} \mathrm{c}_{\mathrm{pp}}
$$

Following Vargas and Bejan; Alebrahim and Bejan $[17,18]$, the entropy generation number $\left(\mathrm{N}_{\mathrm{s}}\right)$ is obtained by dividing the entropy generation rate by the minimum capacity flow rate. Thus, $\mathrm{N}_{\mathrm{s}}$ was obtained by using $\mathrm{C}_{\mathrm{min}}$ in Equation (4) to scale $\dot{\mathrm{S}}_{\text {gen }}$ in equation (1). Also, the ambient properties were used to scale all temperatures and pressures in the expressions. That is:

$$
\dot{\mathrm{T}}_{\mathrm{g}}=\frac{\mathrm{T}_{\mathrm{g}}}{\mathrm{T}_{\mathrm{a}}} ; \dot{\mathrm{P}}_{\mathrm{g}}=\frac{\mathrm{Pg}_{\mathrm{g}}}{\mathrm{P}_{\mathrm{a}}}
$$

The $\mathrm{N}_{\mathrm{s}}$ equation was obtained as:

$$
\mathrm{N}_{s}=\frac{\dot{S}_{g e n}}{\dot{\mathrm{m}}_{\mathrm{p}} \mathrm{c}_{\mathrm{pp}}}=\frac{1}{\dot{\mathrm{m}}_{\mathrm{p}} \mathrm{c}_{\mathrm{pp}}}\left[\dot{\mathrm{m}}_{\mathrm{p}}\left(\mathrm{c}_{p p} \operatorname{In} \frac{T_{g}}{T_{p}}-\mathrm{R}_{\mathrm{p}} \operatorname{In} \frac{P_{g}}{P_{p}}\right)+\dot{\mathrm{m}}_{\mathrm{w}}\left(\mathrm{c}_{p w} \operatorname{In} \frac{T_{S}}{T_{w}}-\mathrm{R}_{\mathrm{w}} \operatorname{In} \frac{P_{S}}{P_{w}}\right)+\frac{\left(\dot{\mathrm{m}}_{\mathrm{p}} \mathrm{c}_{\mathrm{pp}}\left(T_{p}-T_{g}\right)+\dot{\mathrm{m}}_{\mathrm{w}} \mathrm{c}_{\mathrm{pw}}\left(T_{w}-T_{S}\right)\right)}{T_{a}}\right]
$$

Simplifying equation (6) gives:

$$
\mathrm{N}_{s}=\left(\operatorname{In} \frac{\dot{\mathrm{T}}_{\mathrm{g}}}{\dot{\mathrm{T}}_{\mathrm{p}}}-\mathrm{k}_{p} \operatorname{In} \frac{\dot{\mathrm{P}}_{\mathrm{g}}}{\dot{\mathrm{P}}_{\mathrm{p}}}\right)+\mathrm{y}\left(\operatorname{In} \frac{\dot{\mathrm{T}}_{\mathrm{s}}}{\dot{\mathrm{T}}_{\mathrm{w}}}-\mathrm{k}_{w} \operatorname{In} \frac{\dot{\mathrm{P}}_{\mathrm{s}}}{\dot{\mathrm{P}}_{\mathrm{w}}}\right)+\left(\dot{\mathrm{T}}_{\mathrm{g}}-\dot{\mathrm{T}}_{\mathrm{p}}\right)+\mathrm{y}\left(\dot{\mathrm{T}}_{\mathrm{s}}-\dot{\mathrm{T}}_{\mathrm{w}}\right)
$$

And by collecting the terms involving y together, equation (7) becomes:

$$
\text { Ns }=\left(\operatorname{In} \frac{\dot{\mathrm{T}}_{\mathrm{g}}}{\dot{\mathrm{T}}_{\mathrm{p}}}-\mathrm{k}_{p} \operatorname{In} \frac{\dot{\mathrm{P}}_{\mathrm{P}}}{\dot{\mathrm{P}}_{\mathrm{p}}}\right)+\left(\dot{\mathrm{T}}_{\mathrm{g}}-\dot{\mathrm{T}}_{\mathrm{p}}\right)+\mathrm{y}\left(\left(\operatorname{In} \frac{\dot{\mathrm{T}}_{\mathrm{s}}}{\dot{\mathrm{T}}_{\mathrm{w}}}-\mathrm{k}_{w} \operatorname{In} \frac{\dot{\mathrm{P}}_{\mathrm{s}}}{\dot{\mathrm{P}}_{\mathrm{w}}}\right)+\left(\dot{\mathrm{T}}_{\mathrm{s}}-\dot{\mathrm{T}}_{\mathrm{w}}\right)\right)
$$

where:

$$
\mathrm{y}=\frac{\dot{\mathrm{m}}_{\mathrm{w}} \mathrm{c}_{\mathrm{pw}}}{\dot{\mathrm{m}}_{\mathrm{p}} \mathrm{c}_{\mathrm{pp}}} ; \mathrm{k}_{p}=\frac{\mathrm{R}_{\mathrm{p}}}{\mathrm{c}_{\mathrm{pp}}} \text { and } \mathrm{k}_{w}=\frac{\mathrm{R}_{\mathrm{w}}}{\mathrm{c}_{\mathrm{pp}}}
$$

\section{GEOMETRY OF THE BOILER HEAT EXCHANGING UNIT}

For a fire-tube steam boiler which is the focus of this work, the heat exchanging unit typifies a cross-flow, shell and tube heat exchanger. Hot flue gas flows through the tubes in a number of passes before going out into the atmosphere through the exhaust pipe. Water flows through the boiler shells around the tubes. As such, there are four major dimensions that describe the geometry of the fire-tube boiler heat exchanging unit under consideration. They are the diameter of fire tube, $d_{t}$; length of fire tube, $L_{t}$; diameter of boiler shell, $d_{s}$ and length of boiler shell, $L_{s}$. It is assumed that $d_{s}$ and $L_{s}$ are fixed by the boiler surface type. Thus, $d_{t}$ and $L_{t}$ remain the geometric parameters that play trade-off roles which lead to the minimization of $\mathrm{N}_{\mathrm{s}}$. The geometry is subject to its volume constraint;

$$
\mathrm{V}=\frac{\pi}{4} d_{t}{ }^{2} L_{t}
$$

Thus, the entire entropy minimization procedure is placed on a fixed volume basis by using $\mathrm{V}^{1 / 3}$ as length scale in the non-dimensionless formulation of all the lengths: 


$$
\left(\dot{d}_{\mathrm{t}}, \mathrm{L}_{\mathrm{t}}, \dot{d}_{\mathrm{s}}, \mathrm{L}_{\mathrm{s}}\right)=\frac{\left(\mathrm{d}_{\mathrm{t}} \mathrm{L}_{\mathrm{t}}, \mathrm{d}_{\mathrm{s}}, \mathrm{L}_{\mathrm{s}}\right)}{\mathrm{v}^{1 / 3}}
$$

According to Patel and Mavani [19], the pressure drop in the tube is given by the expression:

$$
P_{p}-P_{g}=\left(4 f \frac{L N_{p}}{d}\right) \frac{G^{2}}{2 \rho}
$$

$G=\frac{\dot{\mathrm{m}}_{p}}{A_{t}}=$ mass velocity of the hot product, $\mathrm{A}_{\mathrm{t}}=\frac{\mathrm{N}_{\mathrm{t}} \pi d_{t}^{2}}{4 \mathrm{~N}_{\mathrm{p}}}=$ total area of the tubes. Using the atmospheric pressure $\left(\mathrm{P}_{\mathrm{a}}\right)$ and $\mathrm{V}^{1 / 3}$ to scale pressure and length parameters respectively in equation (12), and substituting for $G$ and $\mathrm{A}_{t}$, the pressure drop equation assumes the following dimensionless form:

$$
\dot{\mathrm{P}}_{p}-\dot{\mathrm{P}}_{\mathrm{g}}=\frac{32 \dot{\mathrm{m}}_{\mathrm{p}}{ }^{2} \mathrm{~N}_{\mathrm{p}}{ }^{3}}{\pi^{2} \mathrm{P}_{\mathrm{a}} \mathrm{d}_{\mathrm{t}}^{4} \rho \mathrm{VV}^{4} / 3 \mathrm{~N}_{\mathrm{t}}{ }^{2}}\left(\frac{\mathrm{L}_{\mathrm{t}}}{\mathrm{d}_{\mathrm{t}}}\right)
$$

Combining Equations (8) and (13) shows that $\mathrm{N}_{\mathrm{s}}=\mathrm{f}\left(\mathrm{L}_{\mathrm{t}}, \mathrm{d}_{\mathrm{t}}\right)$.

\section{COMPUTATIONAL SOLUTION OF THE ENTROPY GENERATION NUMBER (Ns) AND PRESSURE DROP EQUATIONS}

In order to determine the extent of entropy generation due to heat transfer and fluid flow in the system, computer codes were developed in FORTRAN 95 to solve equations (8) and (13). Operational data of a fire tube steam boiler that uses diesel as its fuel were used to illustrate the minimization technique being investigated in this study. Ohijeagbon et al., $2013^{\mathrm{b}}$ [20] have obtained numerical values for the thermodynamic properties of material streams for this particular steam boiler.

Steam pressure $P_{s}$ and water pressure $P_{w}$ at their respective temperatures were obtained from Rogers and Mayhew [21]. Taking ambient temperature and pressure as $T_{a}=298 \mathrm{~K}$ and $\mathrm{P}_{\mathrm{a}}=1.01325 \mathrm{bar}$, dimensionless temperature and pressure values were computed for the streams using equation (5). The properties $R_{w}=0.3473$ $\mathrm{kJ} / \mathrm{kgK}$ and $\mathrm{C}_{\mathrm{pw}}=4.2385 \mathrm{~kJ} / \mathrm{kgK}$ for water at $353 \mathrm{~K}$ were obtained directly from the thermodynamic properties table. However, values for these properties for hot products of combustion of diesel were not obtainable directly from the table. Guha [22] gave the following equations for obtaining each of these properties:

$$
\frac{C_{\mathrm{p}, \text { combust }}}{C_{\mathrm{p}, \text { air }}}=\frac{1+r_{\mathrm{fa}}\left(\Re J_{0}+J_{1} T-\frac{J_{2}}{T_{2}}\right)}{1+r_{\mathrm{fa}}}
$$

and

$$
\frac{R_{\text {combust }}}{R_{\text {air }}}=\frac{1+\Re r_{\mathrm{fa}}}{1+r_{\mathrm{fa}}} .
$$

Also specified were $\Re=0.969, \mathcal{J}_{0}=2.420, \mathcal{J}_{1}=0.0002982$, and $\mathcal{J}_{2}=77800$ for diesel. In equations (14) and (15), $r_{\mathrm{fa}}=$ actual air fuel ratio, $\Re, \mathcal{J}_{0}, \mathcal{J}_{1}$, and $\mathcal{J}_{2}$ are constants based on fuel type, $C_{\mathrm{p}, \text { combust }}=$ specific heat at constant pressure for combustion product and $R_{\text {combust }}=$ gas rate constant for combustion product. According to [7], $r_{\mathrm{fa}}$ may be taken as 17 for diesel operated boilers.

The constants $\mathrm{y}, \mathrm{k}_{\mathrm{p}}$ and $\mathrm{k}_{\mathrm{w}}$ were determined using Equation (9).

The unknown terms on the right hand side of dimensionless pressure drop equation (13) were determined from the fire-tube geometry. The maximum allowable fire-tube volume $\mathrm{V}$ was determined from equation (10). The friction factor (f) is a constant, and it was determined from Fanning friction factor chart for flow through cylindrical conduit, which presents values for friction factor as a function of Reynolds number $(\mathrm{Re})$ and relative roughness of pipe [23]. 


\section{RESULTS AND DISCUSSION}

The entropy minimization procedure involved translating the entropy generation number equation (8) and dimensionless pressure drop equation (13) into computer codes using FORTRAN 95. The codes were written in such a way that each of the fire-tube dimensionless diameter and length values were varied in turn, with the other kept constant, taking into consideration the maximum allowable volume constraint. In the first instance, $\mathrm{d}_{\mathrm{t}}$ was varied between 0.25 and 0.50 at interval 0.01 , while keeping $\mathrm{L}_{\mathrm{t}}$ constant at 2.5 . Thus, $\mathrm{N}_{\mathrm{s}}$ values that correspond to each $d_{t}$ value were obtained.

\subsection{Effects of fire-tube diameter on pressure drop}

Figure 2 shows the relationship between the diameter of the fire-tube and pressure drop. As it would be expected, the pressure drop in fire-tube decreases as the fire-tube diameter increases. During the design of heat exchangers, a maximum allowable value of pressure drop is usually specified. This is because it is often required to keep pressure drop in heat exchanging units as minimum as possible, so as to minimize cost due to pumping. According to [6], the primary aim of such designs is to obtain a high heat transfer rate without exceeding the allowable pressure drop. Also, pressure drop has a significant effect on the level of irreversibility in a system.

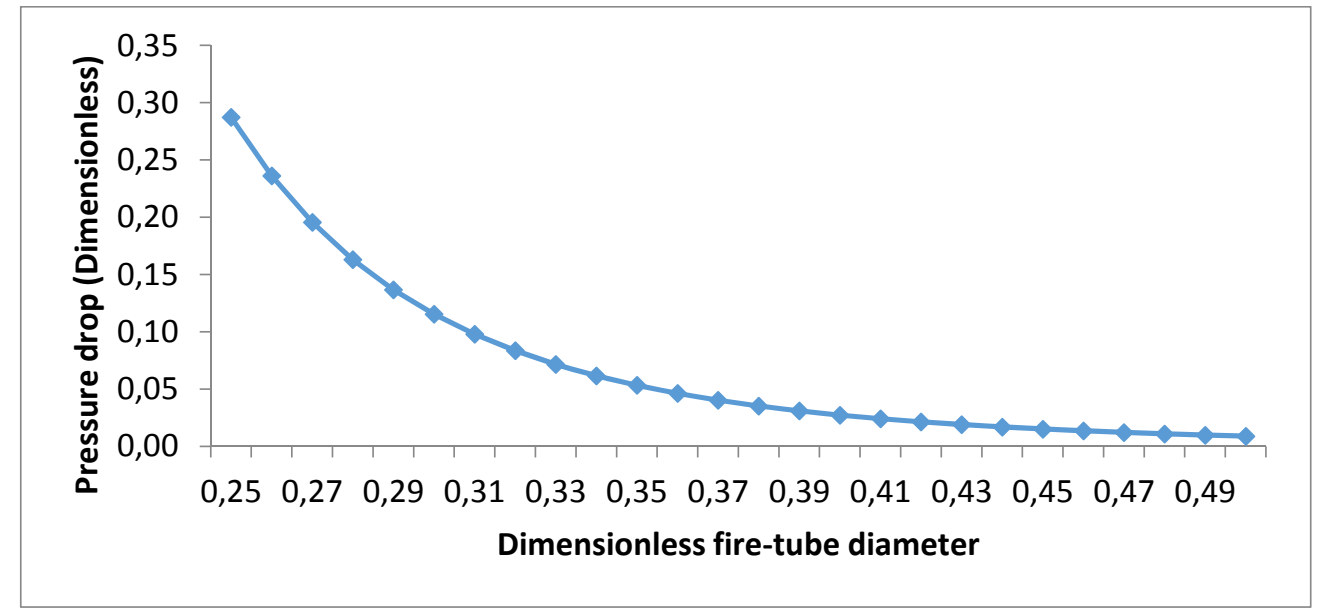

Fig. 2. Pressure drop in fire-tube as a function of diameter.

5.2. Effects of fire-tube pressure drop on entropy generation, at dimensionless length of $\mathbf{2 . 5}$

Figure 3 shows the relationship between pressure drop in the fire-tube and entropy generation number. Pressure drop in the fire-tube has a significant effect on entropy generation rate in the system. The increase in fire-tube pressure drop increases entropy generation in the system.

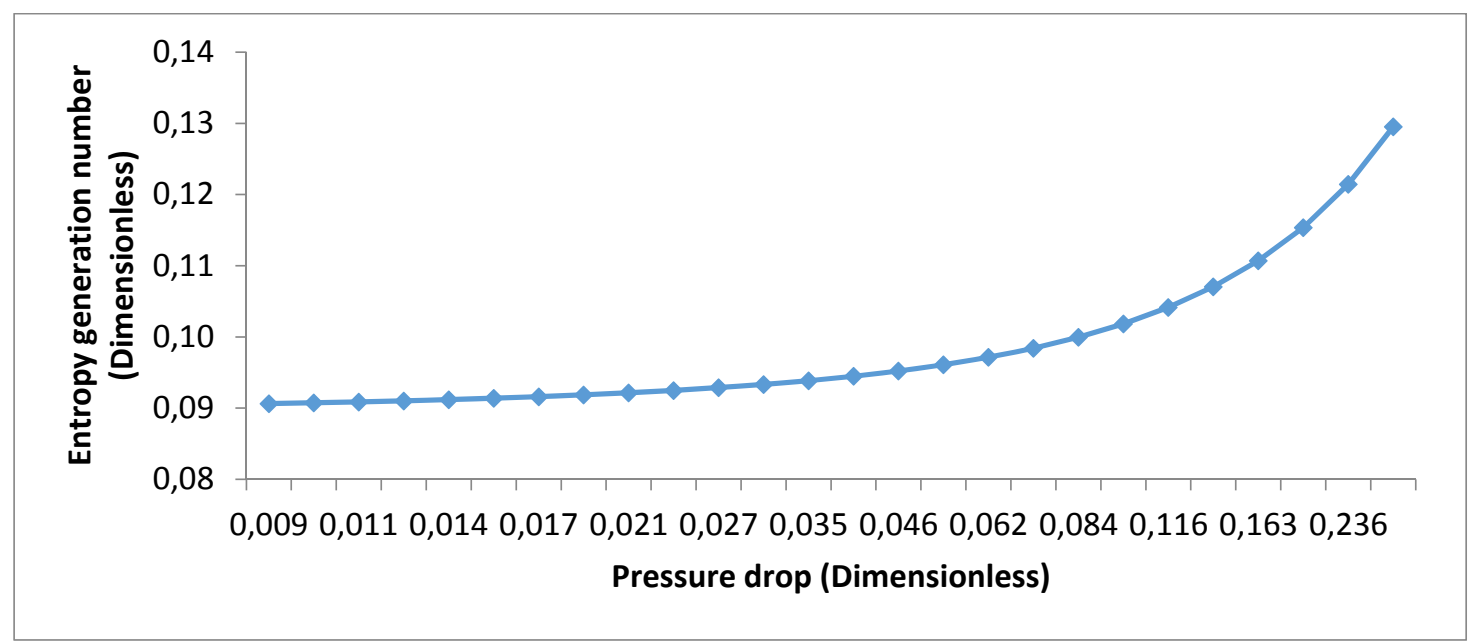

Fig. 3. Entropy generation number as a function of pressure drop. 


\subsection{Effects of fire-tube diameter on entropy generation}

Figure 4 presents the effect of dimensionless fire-tube diameter on entropy generation in the system. As it would be expected, increasing fire-tube diameter lowers entropy generation in the unit. This shows that in order to minimize entropy in the heat exchanging unit of a fire-tube steam boiler, it is required to keep the fire-tube diameter as large as possible. Doing this would reduce pressure drop in fire-tube, which in turn minimizes entropy generation rate and hence irreversibility in the system. The result is in agreement with Assad and Oztop [24], where they reported that entropy generation rate decreases with increasing radius.

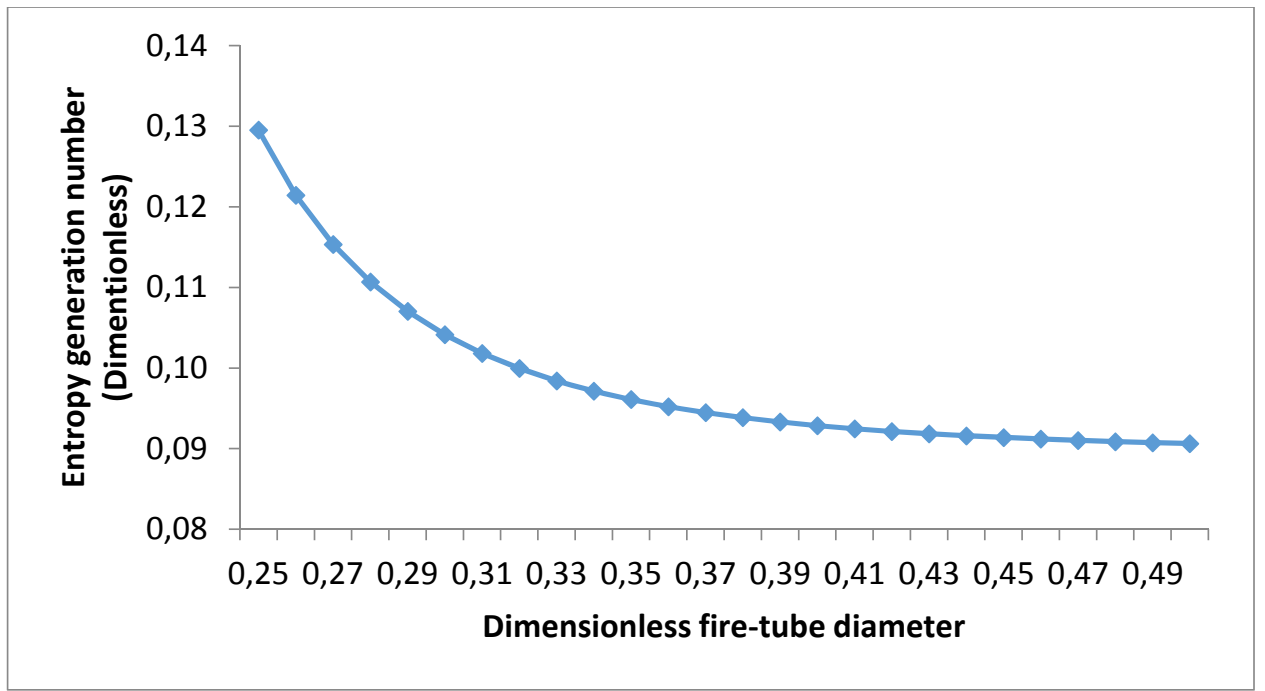

Fig. 4. Entropy generation number as a function of fire-tube diameter.

\subsection{Effects of fire-tube length on pressure drop}

Conversely, $\mathrm{L}_{\mathrm{t}}$ was varied between 0.50 and 5.00 at interval 0.2 , while keeping $\mathrm{d}_{\mathrm{t}}$ constant at 0.35 . Values for $\mathrm{N}_{\mathrm{s}}$ that correspond to each $\mathrm{L}_{\mathrm{t}}$ within the range of variation were also obtained in the same way as mentioned above. Figure 5 shows the relationship between dimensionless length of the fire-tube and pressure drop. The pressure drop in fire-tube increases in direct proportion to the length, giving a linear graph. As aforementioned, it is often required to specify a maximum allowable value of pressure drop during heat exchanger design. It is also shown here that pressure drop has significant effect on the level of irreversibility in a system.

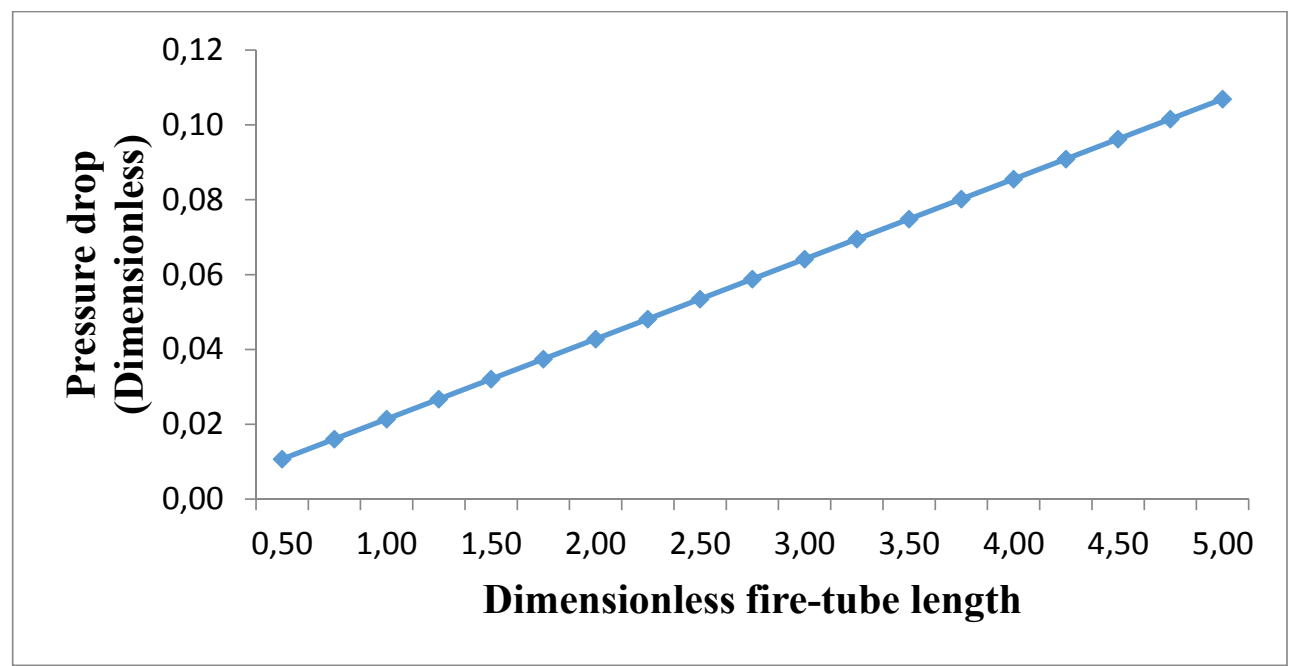

Fig. 5. Pressure drop in fire-tube as a function of length. 
5.5. Effects of fire-tube pressure drop on entropy generation, at constant dimensionless diameter of 0.35 Figure 6 shows the relationship between pressure drop in the fire-tube and entropy generation number. Pressure drop in the fire-tube has a linear relationship with entropy generation rate in the system. The increase in fire-tube pressure drop increases entropy generation in a direct proportion. This corroborates the explanations in section 5.2 .

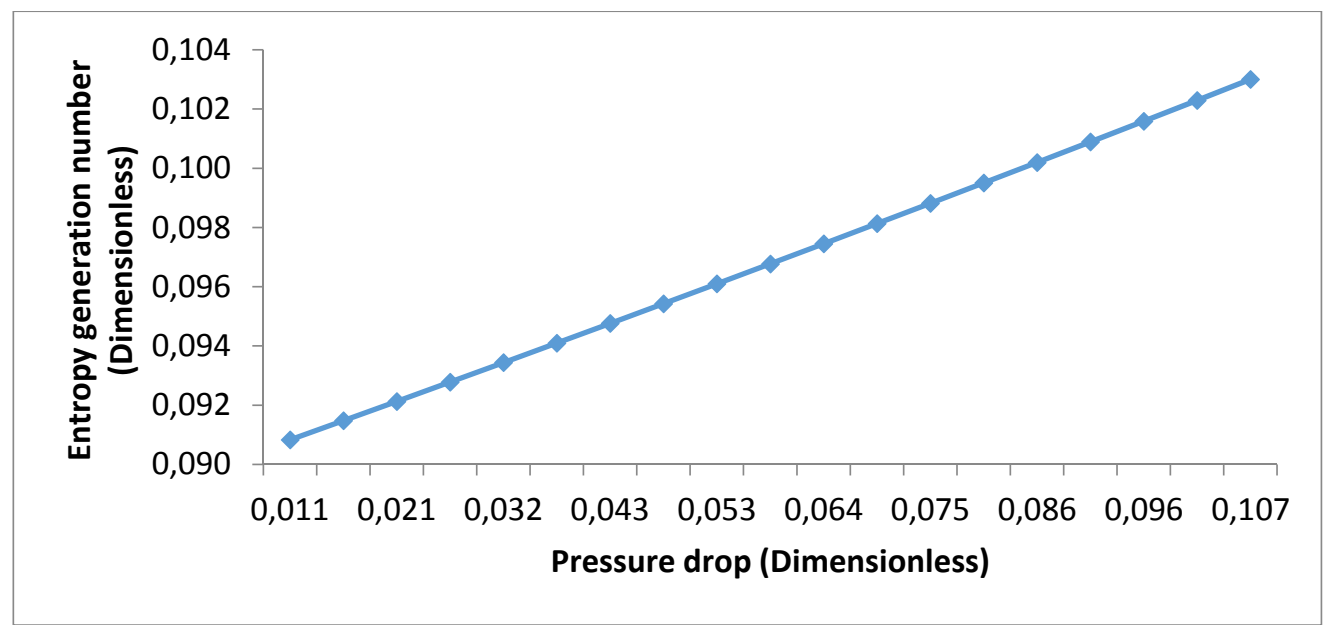

Fig. 6. Entropy generation number as a function of pressure drop.

\subsection{Effects of fire-tube length on entropy generation}

The linear relationship between dimensionless fire-tube length and entropy generation rate in the system is presented in Figure 7. It reveals that increasing fire-tube length results in a proportional increase in entropy generation in the unit, as it would be expected. This result is comparable with that obtained by Sciubba [25], which reported that lowering aspect ratio minimizes entropy.

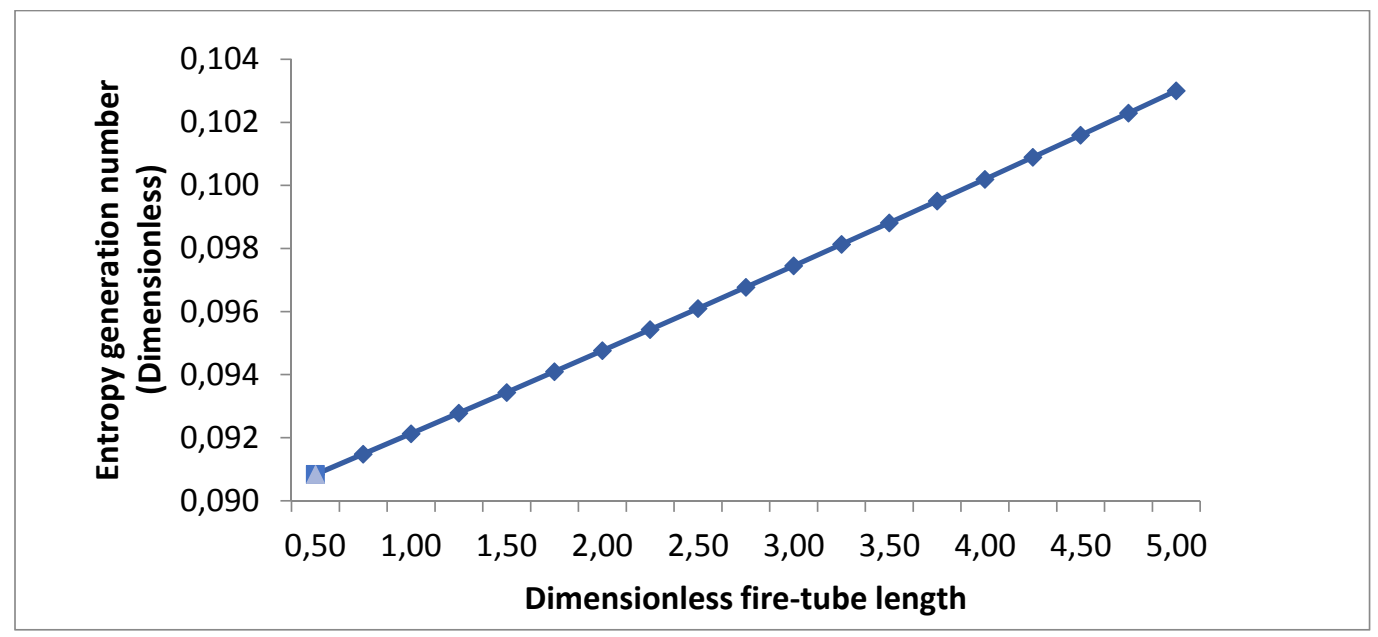

Fig. 7. Entropy generation number as a function of fire-tube length.

It shows that in order to minimize entropy in the heat exchanging unit of a fire-tube steam boiler, it is required to keep the fire-tube as short as possible. Doing this would reduce pressure drop in fire-tube, which in turn minimizes entropy generation rate and hence irreversibility in the system. During design of a fire-tube steam boiler heat exchanger, much attention should be given to the length of fire-tube, since it has direct variation with allowable pressure drop and entropy generation rate in the system. The minimum length that satisfies all requirements should be used in design, for optimum performance of the system.

\subsection{Dimensionless fire-tube diameter and dimensionless length, for Entropy Generation Minimization}

Having investigated the effects of each of fire-tube length and diameter on entropy generation rate in the system, it is required to study the relationship between fire-tube diameter and length with respect to minimum entropy. 
Dimensionless fire-tube diameter was varied between 0.25 and 0.40 , and the corresponding values of dimensionless fire-tube length that gave minimum entropy within the maximum volume constraint were obtained. The relationship is shown in Figure 8. The dimensionless fire-tube length increases exponentially with increase in dimensionless diameter. From the result presented in Figure 8, a correlation equation for Entropy Generation Minimization in the fire-tube boilers' heat exchanging unit was obtained and is given by:

$$
L_{t}=0.011 e^{15.60 d_{t}}
$$

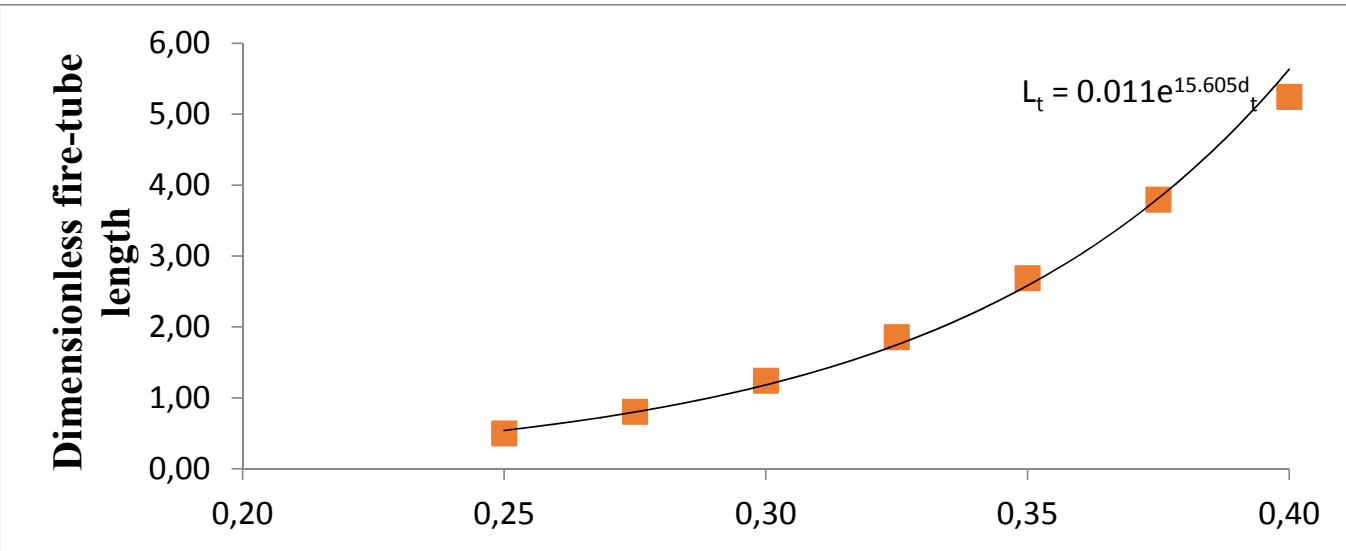

Dimensionless fire-tube diameter

Fig. 8. Relationship between dimensionless fire-tube diameter and dimensionless length that minimizes entropy.

\section{CONCLUSIONS}

The effects of geometric parameters on entropy generation in fire-tube steam boiler's heat exchangers have been investigated. A mathematical equation representing entropy generation rate in the system was developed, and the entropy generation number was determined using appropriate scaling technique. In addition, relationship between entropy generation and geometric features of the heat exchanging unit was obtained. Parametric study showed that pressure drop in the fire-tube and entropy generation in the heat exchanging unit decrease with increasing fire-tube diameter. Conversely, increasing fire-tube length results in proportional increase in both the pressure drop and entropy generation in the unit. This study has contributed to knowledge by establishing a geometry-based correlation equation for entropy generation minimization in the fire-tube boilers' heat exchangers. If well incorporated, this correlation equation would enhance the design of fire-tube steam boilers' heat exchangers.

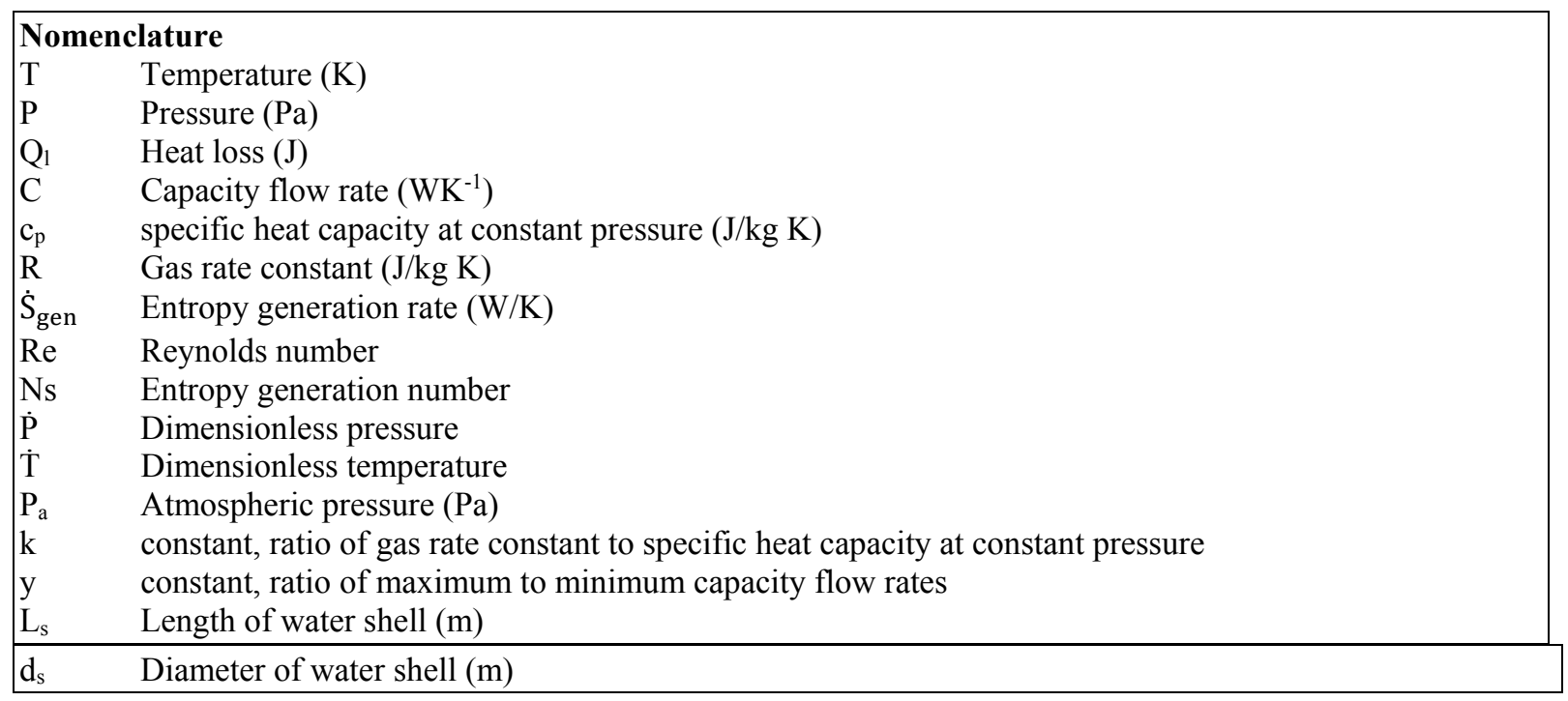




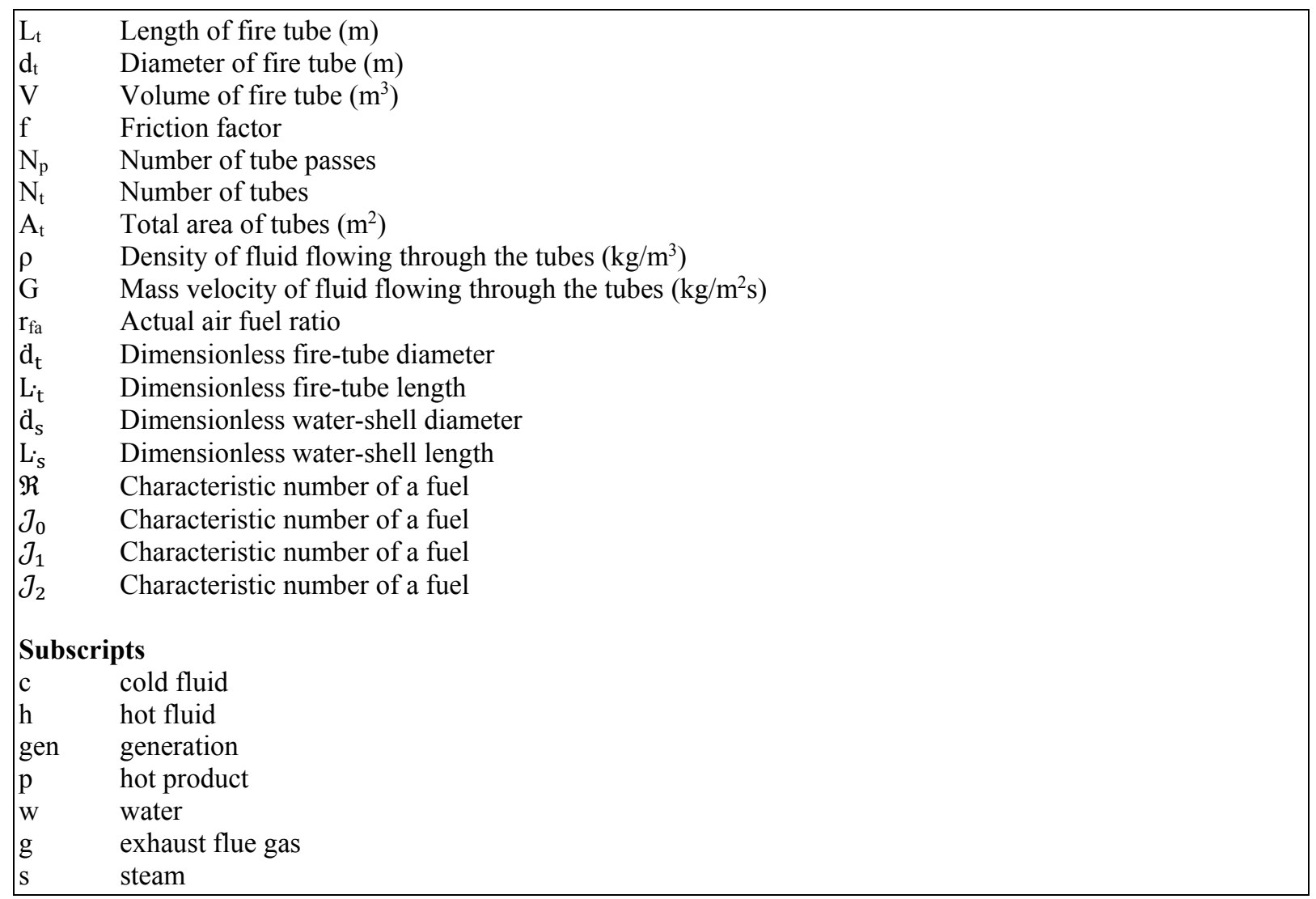

\section{REFERENCES}

[1] Rajput, R.K., A Textbook of engineering thermodynamics, $4^{\text {th }}$ Ed. Laxmi Publications (P) Ltd, New Delhi, 2010.

[2] Giangaspero, G., Sciubba, E., Application of the entropy generation minimization method to a solar heat exchanger: A pseudo-optimization design process based on the analysis of the local entropy generation maps, in ECOS 2012, Proceedings of the $25^{\text {th }}$ International Conference on Efficiency, Cost, Optimization, Simulation and Environmental Impact of Energy Systems, Perugia, Italy, June 26-29, 2012, p. 357-1 - 357-20.

[3] Bejan, A., Entropy generation minimization, CRC Press, Boca Raton, 1996.

[4] Bejan, A., Fundamentals of exergy analysis, entropy generation minimization, and the generation of flow architecture, Int. J. Energy Res., vol. 26, 2002, p. 545-565.

[5] Ordóñez, J.C., Bejan, A., Entropy generation minimization in parallel - plates counterflow heat exchangers. International Journal of Energy Research, vol. 24, no. 10, 2000, p. 843-864.

[6] Nakonieczny, N., Entropy generation in a diesel engine turbocharging system, Energy, vol. 27, 2002, p. $1027-1056$.

[7] Ohijeagbon, I.O., Waheed, M.A., Jekayinfa, S.O., Methodolgy for the physical and chemical exergetic analysis of steam boilers, Energy, vol. 53, 2013, p. 153-164.

[8] Ohijeagbon, I.O., Jekayinfa, S.O., Waheed, M.A., Cumulative exergetic assessment of LPFO utilised steam boilers, Int. J. Exergy, vol. 11, 2012, p.119-135.

[9] Kitto, J.B., Stultz, S.C., Steam: its generation and use, $41^{\text {st }}$ Ed. The Babcock and Wilcox Company, Ohio, USA, 2005.

[10] Saidur, R., Ahamed, J.U., Masjuki, H.H., Energy exergy and economic analysis of industrial boilers, Energy Policy, vol. 38, 2010, p. 2188-2197.

[11] Bejan, A., Entropy generation through heat and fluid flow, Wiley, New York, 1982.

[12] Kim, Y., Lorente, S., Bejan, A., Constructal steam generator architecture, International Journal of Heat and Mass Transfer, vol. 52, 2009, p. 2362-2369.

[13] Kim, Y., Lorente, S., Bejan, A., Steam generator structure: continuous model and design, International Journal of Energy Research, vol. 35, 2011, p. 336-345. 
[14] Kim, Y., Lorente, S., Bejan, A., Constructal multi-tube configuration for natural and forced convection in cross-flow, International Journal of Heat and Mass Transfer, vol. 53, 2010, p. 5121-5128.

[15] Kim, Y., Lorente, S., Bejan, A., Distribution of size in steam turbine power plants, International Journal of Energy Research, vol. 33, 2009, p. 989-998.

[16] Oyekale, J.O., Entropy generation minimization in the heat exchanging unit of steam boiler, LAUTECH, Ogbomoso, Nigeria, 2015.

[17] Vargas, J.V.C., Bejan, A., Thermodynamic optimization of finned cross flow heat exchangers for aircraft environmental control systems, Int. J. Heat and Fluid Flow, vol. 22, 2001, p. 657-665.

[18] Alebrahim, A., Bejan, A., Entropy generation minimization in a ram-air cross flow heat exchanger, International Journal of Applied Thermodynamics, vol. 2, no. 4, 1999, p. 145-157.

[19] Patel, S.K., Mavini, A.M., Shell and tube heat exchanger thermal design with optimization of mass flow rate and baffle spacing, International Journal of Advanced Engineering Research and Studies, vol. 2, no. 1, 2012, p. $130-135$.

[20] Ohijeagbon, I.O., Waheed, M.A., Jekayinfa, S.O., Opadokun, O.E., Developmental design of a laboratory fire-tube steam boiler,"ACTA TechnicaConveniensis - Bulletin of Engineering, Tome VI (Year 2013) FASCICULE (January - March), 2013.

[21] Rogers, G.F.C., Mayhew, Y.R., Thermodynamic and transport properties of fluids. Basil Blackwell, Oxford, 1981.

[22] Guah, A., An efficient generic method for calculating the properties of combustion products, Proc. Instn. Mech. Engrs., vol. 215(A), 2000, p. 375-387.

[23] Holman, J.P., Heat Transfer, $9^{\text {th }}$ Ed. McGraw-Hill, USA, 2002.

[24] Assad, M.E., Oztop, H.F., Parametric study of entropy generation in a fluid with internal heat generation between two rotating cylinders subjected to convective cooling at the surface, International Scholarly Research Network, doi:10.5402/2012/941587.

[25] Sciubba, E., Entropy generation minimization as a design tool. Part 1: analysis of different configurations of branched and non-branched laminar isothermal flow through a circular pipe, International Journal of Thermodynamics, vol. 14, no. 1, 2011, p. 11-20. 